\title{
Maker-Centred Science and Mathematics Education: Lenses, Scales and Contexts
}

Tzu-Hua Wang ${ }^{1} \cdot$ Kenneth Y. T. Lim ${ }^{2}$ - Jari Lavonen ${ }^{3} \cdot$ Alison Clark-Wilson $^{4}$

Published online: 22 June 2019

(C) Ministry of Science and Technology, Taiwan 2019

It is a distinct privilege to bring this special issue - themed on Maker-Centred Science and Mathematics Education - to our readership. Maker movements can trace their origins to the culture of vocational education in Germany since the 1980s. As these early cultures of making and improvisation diffused to the New World, they manifested in more formalised physical spaces as makerspaces - initiated by local interest-based communities as well as by private enterprise - in many cities across the US. Makers design artefacts that can be applied in daily life - often in creative ways. Many of the interest-based maker communities openly share their 'making' process using diverse approaches. That is why many makerspaces have been initiated worldwide as bases from which makers design, create and share. Such phenomena have been described as 'maker movements'. Concurrently, many researchers of education practice have begun to investigate issues relating to the introduction of the concept of makers within education. The accompanying educational discourse on the concept of makers is rooted in Dewey's constructivism and its key feature is 'learning by constructing knowledge through the act of making something shareable' (Martinez \& Stager, 2013, p. 21). This might also be expressed as 'learning by making' and/or 'making for learning'. Over time, the maker concept has been introduced into K-12 systems around the world. In

Tzu-Hua Wang

tzuhuawang@gmail.com

Kenneth Y. T. Lim

kenneth.lim@nie.edu.sg

Jari Lavonen

jari.lavonen@helsinki.fi

Alison Clark-Wilson

a.clark-wilson@ucl.ac.uk

1 National Tsing Hua University, Hsinchu, Taiwan (R.O.C.)

2 Nanyang Technological University, Singapore, Singapore

3 University of Helsinki, Helsinki, Finland

4 University College London, London, UK 
particular, STEM/STEAM education especially emphasises making in terms of the interdisciplinary application of science, technology, engineering, art design and mathematical knowledge, skills and attitudes.

More recently, there has been a somewhat belated recognition of the benefits that might accrue at the intersection of dispositions of making and the enactment of curriculum design. It is the narratives of learning which emerge at this intersection that this special issue is focused on documenting. Sang and Simpson's (2019) study in this special issue affords the reader with a useful panoptic overview, through their interviews with makers in different regions across the globe. Their work provides valuable contextual understanding to $\mathrm{Gu}, \mathrm{Xu}$, and Hong's (2019) study (also in this special issue) - on the development of a Technological Literacy Survey - is one such example of the very necessary efforts being made at this intersection of learning and making. In turn, this paper provides context for another paper in this special issue, namely that describing the work of Hsu, Lee, Ginting, Smith, and Kraft (2019) on making and scientific argumentation.

At the global scale, the outward-oriented economies and geopolitical contexts of Taiwan, Singapore, Finland and England situate themselves at the confluences of major flows of trade, ideas and innovation among different parts of the world. These are particularly well suited to take advantage of the rise of maker-centred learning, in particular, in science and mathematics. Each is a robust economy committed to investments in education and lifelong learning, as a means to engage human capital. Below, the special cases of maker-centred science and mathematics education in Taiwan, Singapore, Finland and England are briefly introduced.

\section{Taiwan}

In 'Future of Education and Skills 2030', the Organisation for Economic Co-operation and Development (OECD) (http://www.oecd.org/education/2030-project/) proposed that future education includes knowledge, skills and attitudes and values. These three parts consist of 'competencies', which are transformed into actions to create the future world with better well-being. Competencies are abilities which can be flexibly utilised and demonstrated in the actions of self-learning, problem solving and getting adapted to the future. Competencies are the most critical skill learners need to live in a future world. To cultivate teaching and learning environments for the aforementioned competencies, the National Tsing Hua University (NTHU) in Taiwan promotes the 'Tsing Hua STEAM School' project (https://tsinghuasteam.org/), working with local governments and K-12 schools to establish the foundation for interdisciplinary education. K-12 students are able to experience interdisciplinary learning and to solve and understand daily life problems via maker practices. Students' computational thinking and programming abilities are developed and their competencies in science, technology, engineering, art design and mathematics are enhanced. The 'Tsing Hua STEAM School' has been advocated and promoted by Prof. Tzu-Hua Wang and Prof. Chi-Hui Lin since 2018. The goal of the 'Tsing Hua STEAM School' is to 'popularize STEAM education, making it applicable in the new Curriculum Guidelines of 12-Year Basic Education of Taiwan, and to provide all students with equal opportunities to receive quality STEAM education so that the goal of cultivation and employment of interdisciplinary talents can be achieved'. 
The 'Tsing Hua STEAM School' is a school alliance, comprised of K-12 schools which agree with its idea of 'Quality STEAM Education for ALL Students'. All schools develop together and share the high-quality Tsing Hua STEAM curriculum, which can be conducted during official school hours. The curriculum is developed based on solving or connecting daily life issues. It corresponds to science and mathematics concepts which students of different grades need to learn, whilst introducing elements including technology, engineering and art design to promote learners' learning effectiveness and motivation. The developed curriculum needs to be applied to teaching practice and assessment mechanisms need to be established. The teaching activities include the process of inquiry, design thinking and maker practice. Regarding inquiry, the '5E learning cycle' (Trowbridge \& Bybee, 1990) and 'modeling-centered scientific inquiry' (Schwarz, 2009) are taken as reference whilst 'design thinking' proposed by Brown (2009) and 'd.school' proposed by the Stanford University (https://dschool.stanford.edu/) are taken as reference for design thinking and maker practice. The teaching activity design of the Tsing Hua STEAM curriculum includes four phases, including discover, define, model \& modelling and transfer. It is named the DDMT teaching model. During teaching, teachers guide students to observe daily life phenomenon. As a start, students actively discover problems to be solved or improved upon in phenomenon. Through class discussion, the focus is put on problems about specific topics. Then after group-based inquiry and design thinking, each group comes up with solutions or prototypes to the problems. In other words, the whole teaching activity starts with the observation of daily life phenomena and the discovery of problems existing in such phenomena. Then learners work in groups to apply knowledge and skills about science, technology, engineering, art design and mathematics to develop multiple problem-solving proposals or prototypes. Besides promoting learners to do interdisciplinary learning, inquiry and practice, these kinds of teaching activities aim to cultivate students' attitudes to actively pay attention to daily life issues and develop their abilities to discover and solve daily life problems.

In the DDMT teaching model, the 'discover' phase includes cultivating an instructional environment of daily life experiences and phenomenon, triggering motivation and guiding students to participate in discovering core problems. The 'define' phase includes agreeing upon the problem the whole class needs to focus on solving, collecting opinions and information and defining problem-solving criteria. Then the whole class brainstorms for all possible solutions based on the criteria. The 'model \& modelling' phase includes teachers guiding each group to materialize solution ideas into illustration examples and make them into solution proposals. Students design small experiments to collect data and explain reasons and the theoretical bases of their problem-solving proposals. Each group would present and explain its proposal to other groups; based on suggestions of teachers and peers, the proposal should be revised. Then, each group of students chooses a solution proposal they think the most appropriate from among all of the proposals and make it into a model or prototype. The model or prototype is tested to manufacture the final product to solve the problem. In the 'transfer' phase, each group needs to describe the similar scenario where the product can be applied (near transfer) to and also, the different scenarios where the product can be applied to (far transfer). Teachers and students also need to evaluate the effectiveness of the product in these different scenarios.

In addition to the curriculum, the 'Tsing Hua STEAM School' also establishes the international STEAM education exchange mechanism. Teachers and students have 
opportunities to publicly present their achievements and perform teaching and learning exchange with outstanding foreign STEAM education units. There are also opportunities for high-achieving STEAM students to do an exchange and advanced studies. These students may be able to join university laboratories and participate in STEAMrelated research projects. More outstanding students can work with engineers and scientists in STEAM-related industries to do research. These exchange mechanisms are expected to encourage students to continuously participate in STEAM courses and enhance people's understanding and interests in STEAM industries and employment opportunities. Besides, the 'Tsing Hua STEAM School' establishes teacher certification and school certification mechanisms. For teacher certification, teachers need to participate in the 'curriculum, instruction and assessment training course' and 'technology competencies training course' of the 'Tsing Hua STEAM School'. They need to leverage the DDMT teaching model to develop the curriculum, perform teaching practice and assessment and collect learning evidence from students. As to the school certification mechanism, schools can only apply when there are at least two certified teachers at school. Schools also need to incorporate the Tsing Hua STEAM curriculum into the school-based curriculum and spend official teaching hours on STEAM education. Since STEAM culture is meant to keep schools and teachers continuously promoting the positive development of STEAM education, the teacher and school certification mechanism established by the National Tsing Hua University aims to cultivate STEAM culture within and between schools. Through mutual support and sharing, the goal of 'Quality STEAM Education for ALL Students' can be achieved.

\section{Singapore}

In Singapore, the education landscape is about to be recontextualised as academic streaming of pupils according to their examination performance - once a backbone of education policy - will be de-emphasised, in favour of what is known as subject-based banding (SBB). Subject-based banding will be progressively rolled out at a policy level across all domain subjects in the formal curriculum in secondary schools in Singapore. This is seen as an explicit recognition that individual learners develop interests and aptitudes differentially from their peers and that the formal curriculum should be sufficiently flexible to accommodate this. Subject-based banding presents tremendous opportunities for the cultivation of dispositions of tinkering, modding and making among a broader cross-section of learners in Singapore, as demonstrated by early work by Dr. Kenneth Y T Lim and his team using open-source environmental sensors through which students interrogate their local environments (http://sites.google. com/site/disciplinaryintuitions/).

The relatively low cost of the sensors affords a fine mesh of potential data sites within any given school campus. In turn, this affords learners access to real-time 'big data' drawn from environments with which they interact on an everyday basis. This has concomitant advantages over more traditional methods, such as the pointillistic and opportunistic approach of having students take readings only during a limited duration using traditional data-loggers.

These networks consist of handheld battery-powered computers (such as micro:bit and Arduino) that are connected to various sensors, such as those measuring air 
pressure, noise levels, ambient light, humidity, pressure and air quality. This so-called Maker Motes system utilises open-source low-cost modular/customisable equipment housed in easily sourced materials such as sandwich boxes and/or water bottles to upload environmental data to the cloud, from which the data can be subsequently accessed and analysed through existing network/mobile infrastructures and/or offline means (Lim, 2017). The sensors are robust enough to be tolerant of irregular power supplies/intermittent network access and/or monsoonal weather conditions.

Therefore, through the use of a network of low cost, open-source, unobtrusive environmental sensors placed throughout the school campus, teachers design curricula which permit and encourage the interrogation of real-world micro-climatic data from within an environment already familiar to the students.

Schools in Singapore have already been using the datasets since 2018 in a proactive manner by staff and students to conceptualise and design measures to improve the quality of the school environment, such as in terms of noise, shade and air quality.

In 2019, a small-scale study was enacted by officers of the Ministry of Education and Dr. Lim's research team from the National Institute of Education. The study was conducted with grades eight and nine cohorts during regular curriculum hours, across two academic streams, from April to December 2019.

Typically, an intervention would begin with the teachers introducing the topic for the investigation to the students. Groups of students would then collaboratively decide on how they interpret the investigative process and which local environmental variables and which sites within their school campus would be relevant to carry the investigation. For example, a scenario that arose from the 2019 pilot was the students approached their teacher to suggest the inquiry of whereabouts in the school would be most suitable for self-study during after-school hours; the students decided that relevant variables to monitor would include noise, relative humidity, light and so on.

As the investigation unfolded, teachers would guide students to code their chosen sensors within the context of the formal curriculum. During this initial workshop, students had access to the open-source hardware (either individually or in small groups) and were given sufficient time to go through an orientation activity. They would also have the benefit of having mentor figures (teachers or members of the research team) on hand. Teachers also guided the students in assembling the sensors (such as in terms of the components of the anemometer, wind vane and rain gauge), as well as helped them think through aspects of the design of the protective enclosure of the sensors, taking in to account parameters such as adequate ventilation, protection from monsoonal rain and access to mains power/batteries. Students also decided on coding parameters such as the frequency of data transmission. A subsequent session would see the students actually taking their sensors (which they assembled and coded themselves) out of the classroom into different parts of the school, such as the canteen and the multi-purpose hall. Supported by members of the project team, teachers helped each group of students affix the sensors at their chosen locations. Care was taken to ensure that the sensors were able to be within network range of the router, which - in turn - transmitted data from the sensors to the cloud, from whence it was retrievable through any regular office suite of software as spreadsheets and subsequently re-purposed in to charts, tables, graphs and regular stimulus material in teachers' worksheets and learning resources.

With the sensors and the network up and running within the schools, what remained for the rest of the intervention was for teachers to design and develop curriculum 
packages (at the very least using existing worksheets but this time, using the local datasets from within the students' own lived environments) to take advantage of the availability of the real-time data from the sensors. These learning resources took a variety of scaffolded forms, differentiated according to the students' geographical and mathematical literacies. For example, for academically more able students, the teachers gave them access to the actual raw data in spreadsheet form and tasked them not only to interpret the trends and patterns (and account for anomalies) but also to think about the most appropriate ways to represent the data and their analyses. On the other hand, for academically less able students, the teachers scaffolded the task a little more by first processing the data into simpler charts and graphs before sharing them with their students. The scaffolds were then gradually removed as the students gained confidence and literacy. An important point to note is that because the data is cloud-based, the teacher could design learning tasks to take advantage of the fact that the data could be accessed from a variety of platforms, including tablets and smartphones.

\section{Finland}

The maker movement in Finnish education dates to 1866 when craft education was accepted as a compulsory subject in the school curriculum (Rasinen, Ikonen, \& Rissanen, 2006). The subject has emphasised design, innovation, creativity and aesthetics, as well as the use of science and mathematics knowledge in the design activities. Workshops were established in every school for supporting students design, create and share useful artefacts. Therefore, there has been a long 'maker tradition' in Finnish compulsory school.

In the past 10 years, the challenges of the Finnish education system were discussed in a similar way to Taiwan and Singapore, as described in this introductory section. The discussion was done, for example, in different forums and national projects, such as the National Teacher Education Forum (Ministry of Education and Culture [MEC], 2016) and the Basic Education Forum (MEC, 2018); the following questions have guided the discussion (Vahtivuori-Hänninen et al., 2014):

- What types of competences will be needed in the future?

- What kinds of practices at school produce these competences?

These questions facilitated also the discussion during the design of the National Core curriculum for Basic Education (NCCBE) (Finnish National Board of Education [FNBE], 2014). The NCCBE introduced transversal competences, which were grouped in the following categories: taking care of oneself, managing daily life; multiliteracy; digital competence; working life competence; entrepreneurship; participation involvement; building a sustainable future; thinking and learning how to learn; and cultural competence, interaction and expression. In order to achieve these transversal competences, the curriculum recommends that teachers encourage their students to engage in scientific and engineering practices (cf. Krajcik \& Shin, 2015), like:

- Critical and creative knowledge practices, such as searching for information and generating new ideas 
- Collaborative knowledge building, and the use of knowledge in different situations

- Constructing and working with abstract or concrete artefacts, like texts and concept maps, Lego robots and 3D printers, along with digital tools in different learning environments both in and out of school.

Consequently, the original idea related to the use of workshop in the design and creative activities has resurfaced in the NCCBE.

Recommendations related to scientific and engineering or design practices have also been significant to the maker movement over the past decade. According to Halverson and Sheridan (2014), the maker movement emphasises active involvement in the use of knowledge and creative design, the production of physical and digital artefacts and sharing these artefacts with others. Digital tools and devices have made it possible to promote a new kind of entrepreneurial spirit in terms of designing products and providing services for other people.

In addition to describing the transversal competences included in the NCCBE, the goals for these competences were examined through subject-specific aims of the curriculum. This approach was intended to help teachers understand the meaning of the competences and how they should be developed (Halinen, 2018). The science and technology curriculum, as a part of the NCCBE, emphasised core scientific and technological knowledge, with inquiry and design processes being promoted as necessary for learning science. The inquiry and design processes included both critical and creative thinking, which are also considered to be essential transversal competences.

During the inquiry process, critical thinking is needed to identify research questions and connect a specific claim with evidence. Creative thinking is also required when designing an artefact because students must consider unusual and radical ideas related to the design. Furthermore, they need to develop their critical thinking skills whilst taking into account several points of view related to the design and evaluation of their ideas. Maker activities are also useful for promoting scientific and engineering practices, as they teach students to study both the natural world and the world of design, making them effective for achieving the aims outlined in the NCCBE. Digital tools can be used for building designs that are apt for 3D printers. Whilst engaged in maker activities, students generate innovative ideas, as well as create and develop interesting things in digital and concrete forms, using both new and old technologies. Such activities encourage students to take part in the creation process and start making things on their own (Dougherty, 2012; Martin, 2015).

Many developments and research projects, competitions and TV series have been supportive of the maker movement. For example, the 6-year LUMA-SUOMI program (2013-2019) (https://suomi.luma.fi/blogi/), funded by the Ministry of Education and Culture for $€ 5$ million euros, is responsible for increasing the quality of science learning and outcomes, including creativity and student engagement in cooperation with teachers, schools, parents, administrators and stakeholders.

Currently, there are several research projects in Finland focused on developing innovations in education, including maker activities, that follow the new curriculum. For example, Professor Kai Hakkarainen is leading the Co4-Lab (2018) project (https://www.helsinki.fi/co4lab), which supports pedagogic development in schools by using long-standing research. Practices of invention pedagogy are developed together with schools through repeated explorative cycles of investigation. The project is 
committed to the open sharing of pedagogic innovations and seeks collaboration with schools committed to pedagogic development. Co4-Lab also organises inspiring maker and creative school projects in primary and lower secondary schools.

In a competition called This Is Working-Moving Toy, only certain materials, specified in the list of materials, can be used in the construction of a moving toy. The toy must be creatively designed from materials recycled in the school, so nothing needs to be purchased. This encourages students to think about the rational use of materials: what is needed and how to make it. Ideas should be discovered by the children themselves or in cooperation with one another. The competition is organised each year; local competitions are held all over Finland, followed by a nationwide final competition.

In summary, at a strategic level, the maker movement is well recognised and emphasised in the Finnish NCCBE and in school practice. Several examples of maker-related development and research projects exist, and they continue to support the development of maker-based education.

\section{England}

The current National Curriculum in England defines subject boundaries for 5-19 education, which include mathematics, science, computing and design and technology. In most state-funded schools, the school day is organised around these boundaries, although early years and primary education (5-11 years) facilitates more opportunities for cross-curricular approaches to STEM teaching as the students are normally taught by just one teacher for all subjects. In reality, the English National Curriculum defines the subject content but does not specify any pedagogical approaches, which leave schools and teachers at liberty to devise how students access the STEM curriculum. However, the high-stakes national testing, which does not include formal assessments of (collaborative) group products/outputs in 11-18 STEM education, drives school practices and mitigates against more maker-centred approaches.

Despite this, a number of more innovative approaches have been explored and researched, which include the Sheffield Makey Project (2017-2019), that aim to conduct 'empirical research to determine how makerspaces can foster the digital literacy and creativity skills and knowledge of young children' and to 'develop a conceptual framework for analysing young children's engagement in makerspaces' (Marsh et al., 2017).

Furthermore, the lack of education policy-led direction regarding maker-centred pedagogies does not prevent grass-roots activity in schools in relation to STEM education. In particular, the movements begun by the designers of tangible computing devices such as the BBC micro-bit, pi-top and Kano emphasise the creative opportunities that such devices offer into maker communities. Consequently, English schools that subscribe to the principles of maker cultures are scheduling curriculum time for this.

However, although the national educational policy has not identified the creation of makerspaces (or promoted maker-centred pedagogies), the UK government's Department of Digital Culture, Media and Sport (DCMS, 2017) Digital Strategy does acknowledge that they are 
places where people can learn new skills, and collaborate on projects. Makerspaces also are democratising access to the latest technology, making high-tech equipment like $3 \mathrm{D}$ printers and laser cutters available to everyone. We will bring together people from across sectors to collaborate and support the expansion of makerspaces in public libraries in England (2017).

The government strategy was informed by research conducted by the National Endowment for Science Technology and the Arts (NESTA, 2015), which surveyed the UK in 2015 and identified 97 makerspaces that were located in public libraries, universities and technology hubs, of which approximately 20 offered school programs.

To summarise, the maker community in England exists as a grass-roots movement that is in its infancy with respect to the formal school settings. The current educational policy, whilst not explicitly promoting maker-centred learning in schools, does not prevent such pedagogical approaches.

This special issue presents a number of other papers which complement these moves; an example is Becker and Jacobsen's (2019) work describing efforts in Canadian schools. Their paper foregrounds the role that a maker-centred curriculum might play in nurturing ontological understanding among novices. Another paper in this issue which investigates the affordances of making to the development of ontological understanding and epistemological appropriation is contributed by Ke, Clark, and Uysal (2019). These aforementioned papers, the papers by Chen and Lin (2019) and by Huang, Lin, and Yueh (2019), highlight the affordances of maker-centred learning in a multi-disciplinary curriculum, especially the one which recognises the systems and processes which operate at planetary scales - be they in astronomy or in environmental science - as well as atomic scales, as described by Rosenfeld, Yayon, Halevi, and Blonder (2019), in their paper on Chemistry education in this issue.

Presenting a very different scale of analysis is Braga and Guttmann's (2019) work from Brazil, which brings the focus of the reader down to the very human scale of the knowledge networks in a maker-centred learning environment. Their work is complemented by a paper in this issue by Doorman et al. (2019), which examines collaborative interactions among learners in a mathematics-centred makerspace. Analyses of such networks in these papers afford us insights into assessment for learning.

We hope you will enjoy reading and learning from the papers in this special issue on Maker-Centred Science and Mathematics Education, as much as we have in curating the manuscripts. It remains for us to wish you a fulfilling journey in making and learning.

\section{References}

Braga, M., \& Guttmann, G. (2019). The knowledge networks in a makerspace: The topologies of collaboration. International Journal of Science and Mathematics Education, 17(this issue).

Becker, S., \& Jacobsen, M. (2019). "How can I build a model if I don't know the answer to the question?": Developing student and teacher sky scientist ontologies through making. International Journal of Science and Mathematics Education, 17(this issue).

Brown, T. (2009). Change by design: How design thinking transforms organizations and inspires innovation. New York, NY: HarperCollins. 
Chen, C. S., \& Lin, J. W. (2019). A practical action research study of the impact of maker-centered STEM$\mathrm{PjBL}$ on a rural middle school in Taiwan. International Journal of Science and Mathematics Education, 17 (this issue).

Department for Digital Culture, Media and Sport (DCMS). (2017). UK Digital Strategy. Retrieved from https://www.gov.uk/government/publications/uk-digital-strategy/uk-digital-strategy .

Doorman, M., Bos, R., de Haan, D., Jonker, V., Mol, A., \& Wijers, M. (2019). Making and implementing a mathematics day challenge as a makerspace for teams of students. International Journal of Science and Mathematics Education, 17(this issue).

Dougherty, D. (2012). The Maker Movement. Innovations, 7(3), 11-14.

Finnish National Board of Education (FNBE). (2014). The National Core Curriculum for Basic Education. Helsinki, Finland: FNBE National Board of Education. Retrieved Jun. 2, 2019 from http:/www.oph. fi/ops2016. Accessed 2 June 2019.

Gu, J., Xu, M., \& Hong, J. (2019). Development and validation of a technological literacy survey. International Journal of Science and Mathematics Education, 17(this issue).

Halinen, I. (2018). The new educational curriculum in Finland. In M. Matthes, L. Pulkkinen, C. Clouder, \& B. Heys (Eds.), Improving the quality of childhood in Europe (7th ed., pp. 75-89). Brussels, Belgium: Alliance for Childhood European Network Foundation. http://www.allianceforchildhood. eu/files/Improving_the_quality_of_Childhood_Vol_7/QOC $\% 20 \mathrm{~V} 7 \% 20 \mathrm{CH} 06 \% 20 \mathrm{DEF} \% 20 \mathrm{WEB}$.pdf . Accessed 2 June 2019.

Halverson, E. R., \& Sheridan, K. (2014). The maker movement in education. Harvard Education Review, 84(4), 495-504.

Hsu, P. S., Lee, E. M., Ginting, S., Smith, T. J., \& Kraft, C. (2019). A case study exploring non-dominant youths' attitudes toward science through making and scientific argumentation. International Journal of Science and Mathematics Education, 17(this issue).

Huang, T. C., Lin, W., \& Yueh, H. P. (2019). How to cultivate an environmentally responsible maker? A CPS approach to a comprehensive maker education model. International Journal of Science and Mathematics Education, 17(this issue).

Krajcik, J., \& Shin, N. (2015). Project-based learning. In K. Sawyer (Ed.), The Cambridge handbook of the learning sciences (2nd ed., pp. 275-297). New York, NY: Cambridge University Press.

Ke, F., Clark, K. M., \& Uysal, S. (2019). Architecture game based mathematical learning by making. International Journal of Science and Mathematics Education, 17(this issue).

Lim, K. Y. T. (2017). Journeys in the making: Supporting thinkering through Maker Motes. In K. Y. T. Lim (Ed.), Landscapes of participatory making, modding and hacking: Maker culture and makerspaces (pp. 83-105). Newcastle upon Tyne, England: Cambridge Scholars Publishing.

Marsh, J., Kumpulainen, K., Nisha, B., Velicu, A., Blum-Ross, A., Hyatt, D., . . Thorsteinsson, G. (2017) Makerspaces in the early years: A literature review. University of Sheffield, England: MakEY Project.

Martin, L. (2015). The promise of the Maker Movement for education. Journal of Pre-College Engineering Education Research (J-PEER), 5(1), 30-39. https://doi.org/10.7771/2157-9288.1099.

Martinez, S. L., \& Stager, G. S. (2013). Invent to learn: making, tinkering, and engineering in the classroom. Torrance, CA: Constructing Modern Knowledge Press.

Ministry of Education and Culture (MEC). (2016). Opettajankoulutuksen kehittämisohjelma [Development program for teachers' -re- and in-service education]. https://minedu.fi/documents/1410845/3985888 /Opettajankoulutuksen+kehitt\%C3\%A4misohjelma+\%2813.10.2016\%29/50c36e4b-7aff-4a0b-8b360199flebe7e8/Opettajankoulutuksen+kehitt\%C3\%A4misohjelma+\%2813.10.2016\%29.pdf. Accessed 16 June 2019.

Ministry of Education and Culture (MEC). (2018). Peruskoulufoorumi luovutti esityksensä peruskoulun kehittämislinjauksiksi [The basic school forum published the developmental plan for the basic school]. http://minedu.fi/artikkeli/-/asset_publisher/peruskoulufoorumi-luovutti-esityksensa-peruskoulunkehittamislinjauksiksi . Accessed 2 June 2019.

National Endowment for Science, Technology and the Arts (NESTA). (2015). UK Makerspaces: The data. https://www.nesta.org.uk/archive-pages/uk-makerspaces-the-data/. Accessed 2 June 2019.

Rasinen, A., Ikonen, P., \& Rissanen, T. (2006). Are girls equal in technology education? In M. J. De Vries \& I. Mottier (Eds.), International handbook of technology education: Reviewing the past twenty years (pp. 448-459). Rotterdam, Netherlands: Sense Publishers.

Rosenfeld, S., Yayon, M., Halevi, R., \& Blonder, R. (2019). Teachers as makers in chemistry education - An exploratory study. International Journal of Science and Mathematics Education, 17(this issue).

Sang, W., \& Simpson, A. (2019). The Maker Movement: A global movement for educational change. International Journal of Science and Mathematics Education, 17(this issue). 
Schwarz, C. V. (2009). Developing preservice elementary teachers' knowledge and practices through modeling-centered scientific inquiry. Science Education, 93(4), 720-744.

Trowbridge, L. W., \& Bybee, R. W. (1990). Becoming a secondary school science teacher (5th ed.). Columbus, $\mathrm{OH}$ : Merrill Publishing Company.

Vahtivuori-Hänninen, S. H., Halinen, I., Niemi, H., Lavonen, J. M. J., Lipponen, L., \& Multisilta, J. (2014). A new Finnish national core curriculum for basic education and technology as an integrated tool for learning. In H. Niemi, J. Multisilta, L. Lipponen, \& M. Vivitsou (Eds.), Finnish innovations and technologies in schools: A guide towards new ecosystems of learning (pp. 33-44). Rotterdam, Netherlands: Sense Publishers. 